\title{
The Impact of Modularization Strategy and Life Cycle Design Concept to Increase Product Variety and Reduce Environmental Burden
}

\author{
A Case Study in Manufacturing Industry
}

\author{
Dira Ernawati ${ }^{1}$, Dwi Sukma D, Endang Pudji \\ Department of Industrial Engineering \\ Universitas Pembangunan Nasional "Veteran" Jawa Timur \\ Surabaya, Indonesia \\ 1diraernawati@yahoo.com
}

\author{
Ni Ketut Sari \\ Department of Chemical Engineering \\ Universitas Pembangunan Nasional "Veteran" Jawa Timur \\ Surabaya, Indonesia
}

\begin{abstract}
The design stage is the greatest stage in determining quality of a product and production process cost. Manufacturers have to apply the concept of supporting the optimization of raw material to produce good quality products at competitive prices. Modularization is an approach to simplify complex products and processes become more efficient. Use modular design in a product can help reduce the capital investment of nearly $50 \%$ and lead time by $30 \%$. Modular design is an important element in the design of the product life cycle. The design life cycle of an activity that aims to minimize the environmental burden. For example, upgrading, reuse, remanufacture, and recycle. The design life cycle is one approach that supports environmental care, especially to maintain the availability of raw materials in the future. By applying the modularization strategy and design life cycle, it can be a good solution to minimize the use of raw materials in the production process. This paper proposes a conceptual framework for evaluating the design of the product life cycle in all phases of the supply chain. This paper also features a case study on several companies. Case studies can provide a real picture of the implementation of the strategy and design modularization of the product life cycle in the manufacturing industry.
\end{abstract}

Keywords - modularization, life cycle design, supply chain

\section{INTRODUCTION}

Economic success of manufacturing companies depends on the ability to identify customer needs, in order to create products that consumers want at a low cost and in a short time. Time to market is the time between design began to be made until the product is ready to be launched to the market to be one important measure for the company. In designing the product, the company should consider a few things, namely quality, low prices, fast and friendly environment [1].

Product is the output of the production process and the result of adding the value of the raw materials. Through the design and development of products expected to be generated new product innovations that can provide certain advantages in overcoming the competition with competitors. Companies must be able to predict changes in consumer desires and responded by increasing the number of product variations [2], [3]. Designing products have an important role in determining the cost of the product, because $80 \%$ of the cost of a product is determined at this stage [4]. This stage also has the highest percentage in determining the quality of the product is approximately $80 \%$. The use of component models by sharing with others will help reduce the capital investment of $50 \%$, in addition to the lead time can also be reduced by up to $30 \%$ [5].

The design life cycle is one of the product design strategies that can be used to minimize the environmental burden and costs during the life cycle of the product. This activity is in the form of grouping the components contained in the product design process based on common life cycle. Examples of life cycle design process is often done upgrading, reuse, maintenance, recycling and disassembly [6]. Modularization is a strategy that can be used to adjust the velocity of the product life cycle more efficiently [7]. Modularization is to disassemble a product or activity complex process into components or modules are simpler [8]. Modular design is one of the basic techniques that are important in order to improve the design of the life cycle [6]. Modularity in product design affects every stage of the product life cycle [9]. Integration between modularization strategy and design life cycle is one way that can be used to produce a variety of products, economically and in accordance with the latest issues concerning sustainable. Based on the search range of previous studies have not been many studies that discuss the application of the two concepts. The purpose of this study is to introduce a conceptual framework of the implementation of both strategies at each stage of the supply chain. Another aim is to give a real picture of the implementation of the strategy and design modularization in the life cycle of the company, this can be achieved through a case study that will be presented in this paper.

\section{LITERATURE REVIEW}

Ernest and comrades [10] stated that Starr [11] first introduced the concept of modularization in the literature "Modular production: A new concept". This concept is 
demonstrated on a product design approach in which a product is assembled from a collection of units that have been standardized components. The study discusses the theories and concepts of modularity largely sourced from the "principle of independence" property Suh [1] which states that a good design will always pay attention to functional independence conditions [12].

The modular design is one way to develop the product by dividing the product into several components or modules are mutually independent [9], [2]. It is intended that these components can be assembled or combined in various ways to produce multiple variations of products that differ from each other. A modular products can be said to depend on the similarity of function and physical design. Components that have similarities in function and physical design is usually called common component. The concept of modularity arises from the need to simplify the setup of complex systems [13]. The overall aim is to describe a complex system into several major sections that allow for split naturally without damaging the overall shape. Ulrich [14] classify modularity in 3 areas of coverage are: (1) modularity in design (MID = modularity in design), (2) modularity in use (MIU = modularity in use), (3) modularity in the production process $(\mathrm{MIP}=$ modularity in production). Some of the benefits of the application of modularization are: (1) saving components, (2) facilitate the increase of value added products, (3) increasing the variety of products, (4) reduce order lead-time [14]. In addition the modular design can increase the variety of products, lower costs, and result in a shorter delivery time [15], [2].

Modular design able to facilitate the process of manufacturing and assembly as well as useful to facilitate the functions of life cycle [7]. Modular design is an effective design technique that connects between the design and the design of the product life cycle. The modular design can improve the performance of the life cycle stages as diverse as disassemblability, maintainability, upgradability, reusability and recyclability. There are few studies divides modularity into several types, including Mikola [2] which divides into 2 types of modularity, ie swapping components and component sharing. Component swapping modularity are several different modules that can be redeemed in exchange and connected to one or more common components to produce a variety of products. Component modularity is sharing some of the modules share the same basic components to create multiple variations of different products.

Salvador [16] split type or modularity into 3 modules, namely (1) basic and Auxillary modules, the modules are used in accordance with its function the same as the previous designs and is considered as the basic modules, such as camera modules and heating module. (2) special modules, used to complete a specific function and not as part of a major, usually no standards but these added functions, such as seal or cover. (3) adaptive modules, used to fit the system or other conditions, for example, speakers modified as needed. The product architecture has a significant influence on all phases of the product life cycle [17]
Salvador [16] also divided into 4 types of modularity based on how the composition of the final product is made, namely (1) component swapping modularity, product variety is made by taking one or more components of the common body product. (2) fabricate-to-fit modularity, product variations created by changing the structure or size of the main component. (3) bus modularity, product variety created by combining several components of a set of component types that have two or more interfaces. (4) sectional modularity, product variety made by mixing and matching a variety of ways a set of components can be combined as long as they surface. Based on the proximity of interfaces between components, modularity types are divided into 3 types, namely (1) slot modularity, if the interface is connected directly. (2) sectional modularity, all components are connected by a link. (3) bus modularity, when the component connected to the separate parts [16].

The life cycle of the product should be designed to be adapted to the conditions required at this stage of product usage. This is one way to design a better life cycle and to apply the concepts of reuse and recycle more effectively. How to reuse the parts do better is to create modular product structure, because the parts products will be structured as modules that can be grouped according to the recycling process. Gehin [18] to build a framework for product life cycle with a closed system, which meant that the life cycle was created simultaneously with the creation of the first component. Within the framework described 4 pieces representing beam processing stages in the product life cycle.

To increase the likelihood of reuse in the module, it is necessary to consider some important characteristics of a module, namely: (1) the stability of technology (technological stability), (2) the ability to increase functionality (functional up-gradability), (3) long life (long life), (4) ease of quality assurance, (5) easy to clean, repair, and others [19].

The process flow in the supply chain can be broken down into two segments: (1) a focus on inbound logistics by setting all kinds of materials and items needed to make the product, and (2) outbound logistics are more focused on the flow of products from the factory to the hands of consumers [9]. While the two kinds of concepts that are often used in the design of products and processes are modularization and postponement, which they both affect the structure of the supply chain. These two concepts are closely related to each other and to apply them properly will provide sustainable competitive advantage to companies throughout the supply chain.

Modularization connected to inbound logistics as a combination of several different components or modules aimed at the process of assembling the final product. While the postponement, on the other side, is linked to outbound logistics for this concept through distribution function to meet market needs. Assembly of different combinations of a set of standardized units that have led to various models of the final product is different and varies. The modular design effectively enhance the flexibility of the final product with the standardization on some parts. 
The concept of modularization of great benefit to the emergence of a variety of research on R \& D management and bring it closer to the supply chain management [20]. In that study concluded that the relationship between the supplier and the interdependent buyer be very high on the condition of the modularization of the system level and the component level becomes less. Interdependent relationship in question is the level of supplier involvement in product development is at the stage of detailed functional and technical specifications given in the supplier. As for the concept design of the same life cycle as modularization concept is included in the product design process which is concerned with determining the type of materials and design processes recycled products.

\section{CONCEPTUAL FRAMEWORK}

Product design is an integral part in the creation of a product. The preparation of the framework is done by analyzing the previous studies that discuss the design of the product. Refering to the purpose of the research is to create a conceptual framework that accommodates modularization strategy and concept design life cycle at every stage supply chain, the research framework formulated as in Figure1. In the picture there are six stages in the supply chain, from design, procurement, production, distribution and storage, use, and end of life (EOL). In each stage describes the condition of the product design modularization strategy and concept design life cycle.

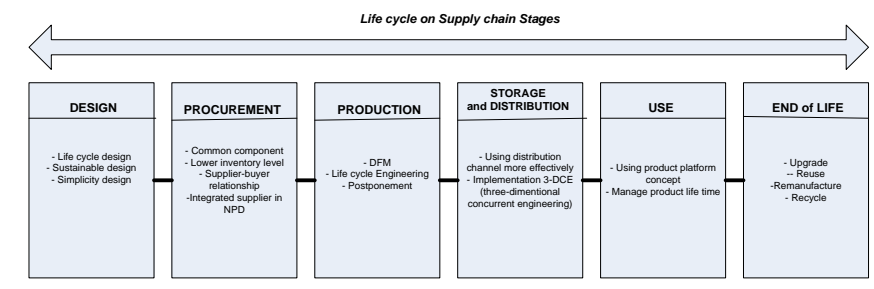

Fig 1. Framework

At the time of going to design a product that all matters relating to the design life cycle must be considered in stages in the supply chain. Because of the design life cycle is no longer a discourse that defined the end the process, but has been taken into consideration in the initial design of the product. In the product design phase (design), should consider the product life cycle design is to make the product design using environmentally friendly materials, with simple design for not too much use of natural materials, while also considering the sustainability throughout the product lifecycle. Phase procurement (procurement) should consider the use of common components when designing products. Since using many common components, will impact the economy at the time of procurement of raw materials, as well as reduces the cost of inventory. So also for the next stage should consider the application of the design life cycle.

\section{RESEARCH APPROACH}

This paper used a case study approach to answer the questions in a product design checklist. The research method enabled this study to gain richer insight through direct observation of industry practise. The case studies were complete when some common factors were identified and relevant theoretical explanation found. Before commencing the case study the authors created a protocol, which included a semi-structured questionnaire and interview procedure whichwas used as a guideline throught the case study.

\section{CASE STUDIES IN MANUFACTURING INDUSTRY}

The case companies were selected after ensuring they were of interest in this area and persons knowledgeable about the case were acccessible. The companies were face highly dynamic technological and market environments requiring flexible modular product design and development. The case firms were selected as they had over five years' $R \& D$ experience successfully developing and producing modular products and so were highly related to the research topic. They had similar external market and production environments, allowing us to focus on the effect of modular product design and life cycle design on their supply chain.

\section{Company 1 : Booth / exhibition tent (case 1)}

Booth or exhibition tent was a conventional single product development project for an industrial customer who made decisions about the product architecture, material use, production and process design. As required by the customer, the case company adopted modular product design and manufactured all the product modules in-house.

The company has implemented a process reuse and recycle in production activities. In the new design, there are about 20$30 \%$ booked part which includes a new design. When creating a new design, some parts of the old design standard size, can be used again. In addition the company to implement the design in its product life cycle by using environmentally friendly raw materials, materials that can be reprocessed according to its kind, and is available to post or place a residual product that can not be reused (disposal).

\section{Company 2 : Electrical panel box (case 2)}

Electrical panel box was a conventional product for an industrial customer or end customer. These firms have more than 30 suppliers, raw material procurement process using routine purchasing system to the core supplier for all kinds of key raw materials such as 18 kinds of plates, paint, locks, hinges. As for the raw materials such as glass and rubber appendages, usually procurement done by inviting a number of suppliers to submit bids.

In production, factory layout settings are in accordance with the stages / work station so that the process runs flowing. There are four engine cut and bend with the operator 3 machines at each work station an average of 6 people. All stages of the process and do their own assembly Total processing time until finishing approximately 5 hours. With the processing time at each stage is different, for example in cutting to 1 product takes 10 minutes.

Production costs consist of $40 \%$ of the plate, $30 \%$ paint, $20 \%$ labor, $10 \%$ material and packaging support. Logistics 
system control using safety stock, especially for materials needed at any time and are directly related to the production process (fast moving) among others, oil, welding wire, $\mathrm{CO}$, hydrogen, and paint. As for the material when needed and quickly run out (slow moving) such as engine parts, stationery, and cardboard for packaging are usually purchased only when needed.

\section{Company 3 : Color television (case 3)}

The production process for these units more on the process of assembly, due process component in the company almost nothing else. The company produces a color TV 14 "and 21" with flat and ultra slim models. Structuring production facilities tailored to the workflow process, and if there is a change process flow rearrangement it can be done as needed.

The company has a warehouse storage of goods remedy. For setting the circulation of goods in the warehouse, the system uses a FIFO (first in first out). The company uses several expeditions partners for the delivery of goods. As for the delivery of products to the outer islands, courier companies use the container to maintain the quality of the product. Structuring systems in the delivery of products there is usually a minimum and maximum limit cubication. Arrangement of products within the warehouse system is done by grouping products according to the unit or model. This is to make it easier when you want to distribute the product. If the overload condition of the warehouse, then that should be done is to change the layout of the arrangement so that it can maximize the function of the warehouse.

In electronic products, the company provides after-sales services such as warranty repairs for 1 year when damage occurs. In addition the company provides advice and complaint boxes in each service center are scattered in several places. This is done to determine the direct response from the users of the product so that it can respond quickly to complaints there.

\section{Company 4 : Standing rack (case 4)}

The company booked a wide variety of components and sub-assemblies making up the product from multiple suppliers. Companies need to determine which supplier can meet all the specifications of a given view of the competitive price and quality. Supplier for furniture comes from within and abroad. The company will look at market conditions before deciding on the purchase price of the main raw material is wood, because the price of raw materials in the domestic suppliers tend to be more stable when compared with the price in the foreign market is very competitive. Type of raw material used for making furniture products can be grouped into two, namely the main raw material (sheet, glass, hinges, doors, accessories), and supplementary materials (packing, glue, sub ported plate / iron buffer). The production process in a standing rack included in the semi-automatic because it uses a high-tech machine that still involves the operator.

\section{Company 5 : Train (case 5)}

The company produces passenger trains and freight trains. It also received orders for a train, according to the model catalog or can also fit the desired requirement In addition to receiving full product orders, it could also serve only manufacture wagon body with no interior components. Components provided by suppliers are divided into two major groups, namely (1) group A for the components are expensive and the process of purchasing long lead time, among other body parts and wheels, (2) Group B for cheap components and lead timenya short, for example chairs, glass and other interior parts. Supplier involvement in the design stage is also quite a lot, such as component selection, where the supplier knows more about market conditions provide input on components that can be used, while the company knows about the needs of the market, see these inputs to increase the quality of the product.

The Company provides after-sales services such as warranty time for components, training for operations and maintenance, provision of technical documents, additional spare parts, maintenance support 1-2 years. A recurring complaint from consumers is about the selection of component specifications, where the rapid component wear and easily damaged. Especially on the engine and sub assembly as a vital function.

TABLE I. COMPARISON OF THE APPLICATION OF MODULARIZATION AND LIFE CYCLE DESIGN

\begin{tabular}{|c|l|l|l|l|l|l|}
\hline No & Case & Variation & Modularity level & $\begin{array}{l}\text { Modularity } \\
\text { type }\end{array}$ & $\begin{array}{l}\text { Complexity } \\
\text { BOM }\end{array}$ & LCD \\
\hline 1 & $\begin{array}{l}\text { Booth/ } \\
\text { exhibition } \\
\text { tent }\end{array}$ & High & Component/part & $\begin{array}{l}\text { Component } \\
\text { swapping }\end{array}$ & High & $\begin{array}{l}\text { Reuse } \\
\text { Recycle }\end{array}$ \\
\hline 2 & $\begin{array}{l}\text { Electrical } \\
\text { panel box }\end{array}$ & High & Component/part & $\begin{array}{l}\text { Fabricate to } \\
\text { fit }\end{array}$ & High & none \\
\hline 3 & $\begin{array}{l}\text { Color } \\
\text { Television }\end{array}$ & Low & Sub assembly & $\begin{array}{l}\text { Fabricate to } \\
\text { fit }\end{array}$ & Medium & none \\
\hline 4 & $\begin{array}{l}\text { Standing } \\
\text { rack }\end{array}$ & High & Component/part & $\begin{array}{l}\text { Component } \\
\text { swapping }\end{array}$ & High & $\begin{array}{l}\text { Reuse } \\
\text { Recycle }\end{array}$ \\
\hline 5 & Train & High & Sub assembly & $\begin{array}{l}\text { Component } \\
\text { swapping }\end{array}$ & High & $\begin{array}{l}\text { Reuse } \\
\text { Recycle } \\
\text { Up } \\
\text { grade }\end{array}$ \\
\hline
\end{tabular}

From this table is concluded that there are manufacturing companies that have not implemented life cycle design (LCD) in the flow process. The company of electricity that produces electrical panel box does not do the reverse on the type of work product because it uses raw materials that can not be repeated the process.

\section{Comparison cases}

The results of the comparison companies are based checklist assessment of product design at all stages of the supply chain. Of all the criteria assessed obtained results of the analysis are as follows:

1. Based on the amount of variation, color television has the least amount of variation, as only a few sub-assembly assembles in outsourcing from other parties. Product variations typically arise because of the number of orders, but for this company has been limiting production to only produce 4 types of color TV. 
2. Based on the number of competitors in the market, electrical panel box products and train industry has lesser competitor.

3. Based on the number of modules, color televisionhas less number of modules, because the company only do the final assembly process.

4. Based on the complexity of the design, standing rack and train has a very complex design when compared with other company.

5. Based on the use of environmentally friendly materials, box panel are not eligible because the materials used are less sensitive to the environment and can not be processed again. In addition, because the company does not have a post to accommodate the product disposal.

Another conclusion that can be drawn are:

1. The five companies have been applying modularization at the level of different modular, ie at the level of components / parts and sub assembly.

2. Determination of modular type in the five companies that were based on some of the literature, among others. Products from these companies are included in the component type swapping, and fabricate-to-fit.

3. Not all companies are applying the concept of life cycle design, this is due to the type of production process and the types of materials that can not be used for reprocessing.

4. Equations contained in each case is in the use of basic design variations within each product, supplier involvement, the use of common components, adjustment of production facilities, process flow adjustments ease in storage and warehousing, ease of use and maintenance products.

From all the discussion about the analysis of case studies in several manufacturing companies, found description of the application of modularization and life cycle design as well as the differences of each case study. From the results it will proceed with the preparation of a mathematical model to determine the effect of the application of modularization design and life cycle of the company's supply chain.

\section{CONCLUSION}

Based on the literature search, there has been no research that discusses the relevance to the overall product life cycle stages in the supply chain, as well as there has been no literature that developed the framework design of the product that is composed of the product, process and supply chain into more detail. Shortcomings and gaps into opportunities and background research. Stages of further research that can be done is the preparation of a design methodology that not only prioritizes product variety, but also able to produce a product that has ease of design for marketing (marketability), easy to process, easy in terms of raw material (supplyability), easy to storage (storageability), easy in terms of delivery (transportability), easy to use (usability), easy of repair (serviceability), easy to process life cycle (reuseability, recycleability, disassemblyability).
Other research opportunities that might be developed is a quantitative analysis to determine the benefits / advantages to be gained in the application of manufacturing and design modularization strategy of product life cycle on a number of aspects of the supply chain. From this description it can be seen that the area of study of modularization and design life cycle still has a lot of opportunities and a chance to develop. But somehow all that will be implemented if all parties, among others, suppliers, manufacturers, distributors, retailers, and consumers have a concern, curiosity and willingness to engage in it. Because to know and useful research is to look at its application in a case study on a few companies, and the response from customers as users.

This paper contains an overview of the application of modularization and design life cycle and its influence on the supply chain. It is also trying to find research opportunities and the chance to learn more about the integration of both. And it is clear that the integration between the two strategies will increase the level of performance of products throughout their life cycle in terms of functional, economic and of the environment.

\section{ACKNOWLEDGMENT}

The authors gratefully acknowledge the constructive and helpful comments of anonymous referees on the earlier version of the manuscript and thanks to the manager of Faculty of Engineering University of Pembangunan Nasional Veteran Jawa Timur Indonesia for supporting.

\section{REFERENCES}

[1] N.P. Suh, "The Principles of Design", Oxford University Press, 1990

]2] F. Kimura, S. Kato, T. Hata, T. Masuda, "Product Modularization for Parts Reuse in Inverse Manufacturing", The university of Tokyo, Tokyo, Japan, 2001

[3] J. Pandremenos, J. Paralikas, Salonitis, K., Chryssolouris, G., "Modularity Concepts for the Automotive Industry : A Critical Review", . CIRP Journal of Manufacturing Science and Technology, vol.1, 148152,2009

[4] J.H. Mikkola, "Modularization Assessment of Product Architecture", Paper presented at the DRUID Winter Conference, 2000

[5] C.Y. Baldwin, Clark, K. B., "Managing in an age of modularity", Harvard Business Review, 75, 84-93, 1997

[6] J.H. Mikkola, "Impacts of supplier-buyer relationships on modularization in new product development", European Journal of purchasing \& Supply management, 5, 197-209, 1999

[7] M. Muffatto, "Introducing a platform strategy in product development", Int. J. Production Economics, 60-61, 145-153, 1999

[8] I.N. Pujawa, Mahendrawathi, E.R., "Supply Chain Management" (Second ed.): GunaWidya Publisher, 2010

[9] F. Salvador, Forsa, C., Rungtusanatham, M., "Modularity, product variety, production volume, and component sourcing : theorizing beyond generic prescriptions", Journal of operation management, 549-575, 2002

[10] M.K. Starr, "Modular-production : A new concept", pp. 131-142, Harvard Business Review, 1965

[11] K. Ulrich, "The role of product architecture in the manufacturing firm", Research Policy, 24, 419-440, 1995

[12] R. Ernst, Kamrad, B., "Evaluation of supply chain structures through modularization and postponement", European Journal of Operation Research, 124, 495-510, 2000

[13] K. Ishii, Juengel, C., Eubanks, C. F., "Design for product variety : Key to product line structuring", Paper presented at the ASME Design Technical Conference, 1995 
[14] Y. Sered, Reich, Y., "Standardization and modularization driven by minimizing overall process effort", Computer - Aided Design, 38, 405416, 2006

[15] A. Gehin, Zwolinski, P., Brissaud, D., "Integrated design of product lifecycle - The fridge case study", CIRP Journal of Manufacturing Science and Technology, 1, 214-220, 2009

[16] G.J. Prasad, Gershenson, J.K, "Modularity in Product Design for Manufacturability", International Journal of Agile Manufacturing, Vol 1(issue 1), 1997
[17] J. Bonvoisin, Halstenberg, F, “A systematic literature review on modular product design", Journal of Engineering Design, Vol. 27, Issue 7, 2016

[18] D.H. Besterfield, "Total Quality Management", New Jersey: PrenticeHall, 1995

[19] Y. Umeda, Fukushige, S., Tonoike, K., Kondoh, S., "Product modularity for life cycle design", CIRP Annals - Manufacturing Technology, 57, $13-16,2008$

[20] J. Wang, Y.F.Shu, "A possibilistic decision model for new product supply chain design", European Journal of Operation Research, 177, 1044-1061, 2007 